\title{
Wet-snow instabilities: comparison of measured and modelled liquid water content and snow stratigraphy
}

\author{
Christoph MITTERER, ${ }^{1}$ Hiroyuki HIRASHIMA, ${ }^{2}$ Jürg SCHWEIZER ${ }^{1}$ \\ ${ }^{1}$ WSL Institute for Snow and Avalanche Research SLF, Flüelastrasse 11, CH-7260 Davos-Dorf, Switzerland \\ E-mail: mitterer@slf.ch \\ ${ }^{2}$ Snow and Ice Research Center, National Research Institute for Earth Science and Disaster Prevention (NIED), Suyoshi-machi, \\ Nagaoka 940-0821, Japan
}

\begin{abstract}
Wet-snow avalanches are difficult to forecast, as the change from stable to unstable snow conditions occurs rapidly in a wet snowpack, often in response to water production and movement. Snow stratigraphy plays a vital role in determining flux behaviour. Capillary barriers or melt-freeze crusts can impede and divert water horizontally over large areas and thus may act as a failure layer for wet-snow avalanches. We present a comparison of measured and modelled liquid water content, $\theta_{w}$, and snow stratigraphy during periods of wet-snow instabilities. Special attention is given to the reproducibility of capillary barriers, ponding of water on melt-freeze crusts and the timing of first wetting and of water arrival at the bottom of the snowpack, because these factors are believed to play a major role in the formation of wet-snow avalanches. In situ measurements were performed in the vicinity of automatic weather stations or close to recent wet-snow avalanches in order to compare them with model results. The simulations are based on two different water flux models incorporated within the 1-D snow-cover model SNOWPACK. The comparison of the two model runs with observed $\theta_{\mathbf{w}}$ and stratigraphy revealed that both water-transport models reproduced the ponding of water on melt-freeze crusts. However, in both models melt-freeze crusts were transformed to normal melt forms earlier than observed in nature, so still existing ponding was not captured by the models. Only one of the models was able to reproduce capillary barriers in agreement with observations. The time of the first wetting at the surface was well predicted, but the simulated arrival time of the wetting front at the bottom of the snowpack differed between the simulations; it was either too early or too late compared with the observation.
\end{abstract}

\section{INTRODUCTION}

The formation of wet-snow avalanches is poorly understood, as are the snowpack processes leading to wet-snow instability. The triggering conditions depend on the complex interaction of water percolation, topography and snowpack properties, making the forecast of wet-snow avalanches notoriously difficult (Schneebeli, 2004). The poor predictability follows from the assumption that the critical state of instability is only achieved under very special conditions so that timing and small differences in forcing become crucial; in other words, the sensitivity to small perturbations (triggers) is highly nonlinear. Although wet-snow avalanches represent a significant hazard, few studies - compared to the formation of dry-snow avalanches - have focused on wetsnow avalanches (Schweizer and others, 2003a).

Wet-snow avalanches often threaten communication lines, and as they cannot easily be triggered by explosives it is essential to forecast times of high release probability relatively accurately so that closures will not be unnecessarily long. Air temperature is the most common proxy for predicting wet-snow instability (McClung and Schaerer, 2006). However, there are many examples showing that air temperature is not always a good predictor (e.g. Kattelmann 1985; Trautman, 2008) and produces too many false alarms (Mitterer and others, 2009). Statistical models which use more sophisticated derivatives (e.g. the integration of air temperature over a certain period) show an improved applicability of this proxy (Baggi and Schweizer, 2009), but most statistical models are only suitable for the climatic region for which they were developed (Romig and others, 2005; Baggi and Schweizer, 2009). In addition, the most important component, the snowpack, is often neglected or represented by data which are sparsely distributed in time and space. Waldner and others (2004) clearly showed that snow stratigraphy plays a major role in determining the flux behaviour of water through snow.

Water flow through the snowpack occurs mostly under unsaturated conditions (Jordan and others, 2008). Following the terminology used in soil physics (Hillel, 2004), water percolation can be classified into two flow regimes: stable flow with a uniform wetting front and unstable flow with preferential flow paths. While, under stable flow conditions, the wetting front advance can mostly be approximated by balancing the interior flow rate with the surface influx (Jordan, 1991), the preferential flow pattern will conduct water much faster downwards, so a simple approximation using the surface influx will underestimate the amount and arrival time of water at a certain depth. Therefore, the application of models based on the Buckingham-Darcy equation is questionable (Waldner and others, 2004). The flow can be impeded and diverted by hydraulic barriers (melt-freeze crusts) and/or capillary barriers. Investigations on capillary barriers under field (Peitzsch and others, 2008) and laboratory conditions (Wankiewicz, 1979) revealed that fine over coarse layering tends to cause ponding. On inclined terrain, impeding layers can divert water laterally and direct it to the bottom of the hill before it penetrates deeper into the snowpack. For deep snowpacks, this can accelerate the arrival time by hours or even days (Jordan and others, 2008). 


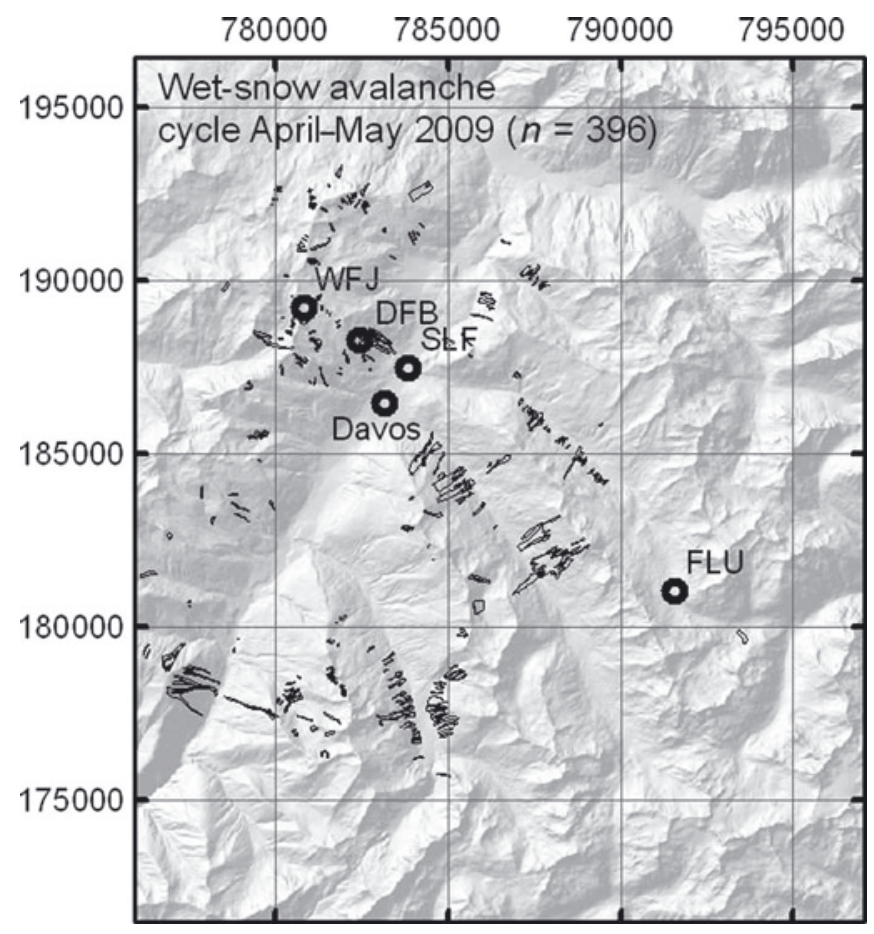

Fig. 1. Automatic weather stations and recorded wet-snow avalanches (outlines) in the surroundings of Davos, Switzerland. Gridlines are $5 \mathrm{~km}$ apart (Swiss coordinate system, CH1903).

Field oservations (Brun and Rey, 1987; Bhutiyani, 1994; Fierz and Föhn, 1995) indicate that snow strength decreases with increasing liquid water content $\theta_{\mathrm{w}}$. However, at low water content $(<3 \%$ by volume) strength is similar to or even larger than dry-snow strength at $0^{\circ} \mathrm{C}$. Only if the water content reaches $\sim 7 \%$ by volume does strength start to considerably decrease. Hence, the transition from the socalled pendular $\left(\theta_{\mathrm{w}}<3 \%\right.$ by volume) to the funicular regime $\left(\theta_{\mathrm{w}}>7 \%\right.$ by volume) (Denoth, 1980) seems to play a major role for the mechanical properties of wet snow.

Forecasting of wet-snow avalanches based only on meteorological parameters has proven unsuccessful. Therefore, it seems obvious that snow stratigraphy and water flow through the snowpack need to be considered explicitly, for example by using snow-cover models such as SNOWPACK (Bartelt and Lehning, 2002; Lehning and others, 2002a,b).

The aim of the present work is therefore to test whether the numerical one-dimensional (1-D) snow-cover model SNOWPACK might be suited to describe the features and processes relevant for wet-snow instability. These include the arrival time of meltwater at the bottom of the snowpack, the ponding on melt-freeze crusts, refreezing of meltwater and the formation of capillary barriers. All these factors are believed to play a major role in the formation of wet-snow avalanches (Baggi and Schweizer, 2009). We compare the results obtained with two different water-transport models incorporated in SNOWPACK with measured $\theta_{\mathrm{w}}$ and observed snow stratigraphy.

\section{DATA}

The input data for all simulations were recorded at three automatic weather stations located above Davos, Switzerland: Weissfluhjoch (WFJ, 2540 ma.s.l.), Dorfberg (DFB, $2145 \mathrm{~m}$ a.s.I.) and Flüelahospiz (FLU, $2390 \mathrm{ma.s.l.).} \mathrm{All}$
Table 1. Meteorological parameters for the three stations Weissfluhjoch (WFJ), Dorfberg (DFB) and Flüela Hospiz (FLU) which were used as input for the SNOWPACK simulations

\begin{tabular}{|c|c|c|c|}
\hline \multirow[b]{2}{*}{ Meteorological parameter } & \multicolumn{3}{|c|}{ Weather station } \\
\hline & Weissfluhjoch & Dorfberg & $\begin{array}{l}\text { Flüela } \\
\text { Hospiz }\end{array}$ \\
\hline $\begin{array}{l}\text { Air temperature, } \\
\text { ventilated }\left({ }^{\circ} \mathrm{C}\right)\end{array}$ & $x$ & $\mathrm{x}$ & - \\
\hline $\begin{array}{l}\text { Air temperature, } \\
\text { not ventilated }\left({ }^{\circ} \mathrm{C}\right)\end{array}$ & - & - & $x$ \\
\hline $\begin{array}{l}\text { Incoming shortwave } \\
\text { radiation }\left(\mathrm{W} \mathrm{m}^{-2}\right)\end{array}$ & $x$ & - & - \\
\hline $\begin{array}{l}\text { Reflected shortwave } \\
\text { radiation }\left(\mathrm{W} \mathrm{m}^{-2}\right)\end{array}$ & $x$ & $x$ & $x$ \\
\hline $\begin{array}{l}\text { Incoming longwave radiation } \\
\left(\mathrm{W} \mathrm{m}^{-2}\right)\end{array}$ & $x$ & - & - \\
\hline Wind direction $\left(^{\circ}\right)$ & $\mathrm{x}$ & $\mathrm{x}$ & $\mathrm{x}$ \\
\hline Wind speed $\left(\mathrm{m} \mathrm{s}^{-1}\right)$ & $\mathrm{x}$ & $\mathrm{x}$ & $\mathrm{x}$ \\
\hline Snow surface temperature $\left({ }^{\circ} \mathrm{C}\right)$ & $\mathrm{x}$ & $\mathrm{x}$ & $\mathrm{x}$ \\
\hline Snow temperatures $\left({ }^{\circ} \mathrm{C}\right)$ & $\mathrm{x}$ & $\mathrm{x}$ & $\mathrm{X}$ \\
\hline
\end{tabular}

three stations are situated in a flat or gently sloped, open field. DFB station was established next to a well-known wetsnow avalanche path slightly above tree line (Fig. 1). The other two stations represent elevations well above tree line.

Recorded meteorological parameters differed slightly between the stations (Table 1), but always included air temperature (TA), relative humidity $(\mathrm{RH})$, wind direction (DW), wind velocity (VW), reflected shortwave radiation (RSWR), snow depth (HS), three different snow temperatures (TS1-3), bottom temperature (T0) and snow surface temperature (TSS). Figure 1 shows the locations of the weather stations and the outlines of the recorded wet-snow avalanches during the period April-May 2009. Wet-snow avalanche activity was calculated according to Schweizer and others (2003b) for all wet-snow avalanches recorded by local observers of the Swiss avalanche warning service for the surroundings of Davos. The index consists of a weighted sum of observed wet-snow avalanches per day. We considered an avalanche as wet avalanche as soon as parts of the snow that released were wet. It was not possible to distinguish between wet slab and wet loose-snow avalanches.

A SNOWPACK simulation was performed for the complete winter season 2008/09 for all three stations using two different water-transport models (see below). We only considered the months March-May for the analysis of the modelled $\theta_{\mathrm{w}}$ since previously the snowpack was still dry. The wetting front was determined from the depth of the liquid water penetration. The model output was calculated every 3 hours.

At the well-equipped Weissfluhjoch study site, outflow data recorded by a $5 \mathrm{~m}^{2}$ lysimeter and biweekly manual snow profiles were available for comparison to simulation results. Continuous $\theta_{\mathrm{w}}$ measurements were recorded with the SnowPower sensor, an experimental flat ribbon cable set-up (Stähli and others, 2004) which uses impedance analyses to obtain the volumetric fractions of ice, air and water within the snowpack. The cable was placed before the beginning of the winter in two different positions. One cable $(10 \mathrm{~m}$ long) was tightened in vertical position $10 \mathrm{~cm}$ above the ground; the other ( $5 \mathrm{~m}$ long) slopes from a mast to the 
bottom of the snowpack and registers an average value of the complete snowpack. Due to problems with running water on the sloped cable, only data from the horizontal cable were used for the presented work. In addition, $\theta_{w}$ profiles were performed using a plate-like capacitive sensor that measures the dielectric permittivity (Denoth and others, 1984). The sensor has to be inserted into the pit wall. We took measurements every $5 \mathrm{~cm}$. One value represents the mean of three consecutive measurements at the same height. Comparison of the capacitive sensor and the ribbon cable was made only for $10 \mathrm{~cm}$ above ground.

At the Dorfberg site, again biweekly to weekly snow stratigraphy observations including detailed $\theta_{\mathrm{w}}$ profiles were performed. No continuous recording of $\theta_{w}$ or outflow was available for the Dorfberg site.

The Flüela Hospiz weather station is situated in a remote area, so only the automatically recorded meteorological parameters were available. A snow profile was performed on 10 May 2009 at the crown of a wet-snow avalanche which had released on the day before, $\sim 2 \mathrm{~km}$ southeast of the station. The profile includes $\theta_{\mathrm{w}}$ measurements taken with the capacitive sensor.

\section{METHODS}

We performed simulations for the winter season 2008/09 using two different water-transport models incorporated into SNOWPACK for the three different stations. The first watertransport model (mode I) is the default model. It is based on the assumption that water transport in the vertical direction is only allowed if $\theta_{\mathrm{w}}$, exceeds a residual water content, $\theta_{\mathrm{r}}$. Based on experimental observations (Kattelmann, 1986), a constant value of 0.08 ( $8 \%$ by volume) is presently used in the model. Above this value, water will be routed directly to the adjoining layer beneath at the rate $\dot{\theta}_{\mathrm{f}}$ which is defined as (Bartelt and Lehning, 2002)

$$
\dot{\theta}_{\mathrm{f}}=\frac{\partial\left(\theta_{\mathrm{w}}-\theta_{\mathrm{r}}\right)}{\partial t}
$$

where $\theta_{\mathrm{w}}$ is the volumetric liquid water content, $\theta_{\mathrm{r}}$ is the residual water content and $t$ is time.

The second water-transport model (mode II) has been newly incorporated into SNOWPACK by Hirashima and others (2010). It considers capillary pressure and hydraulic conductivity and is based on the Van Genuchten-Mualem model (Mualem, 1976; Van Genuchten, 1980), a wellknown water flux model used in soil physics. The model calculates the unsaturated hydraulic conductivity and is based on $\theta_{\mathrm{w}}$, suction and three parameters which account for air entry pressure, pore-size distribution and tortuosity. Yamaguchi and others (2010) used gravity drainage column experiments with different-sized snow grains to obtain the water retention curve for different grain sizes. They showed a clear dependence of the air entry pressure value and the pore-size distribution parameters on grain size, and suggested using a tortuosity factor of 0.5. Based on their findings, Hirashima and others (2010) implemented a parameterization into SNOWPACK.

The arrival time of water at the bottom of the snowpack was calculated by assuming a front advance whenever $\theta_{\mathrm{w}}$ exceeded 0.03 ( $3 \%$ by volume) which corresponds approximately to the transition from the pendular to the funicular regime (Denoth, 1980). The arrival time at the bottom of the snowpack was compared with the outflow of the lysimeter at the Weissfluhjoch site or to wet-snow avalanche activity in the surroundings. Comparison with avalanche activity was only done when avalanches were recorded as fulldepth avalanches.

We analysed the water content profiles obtained with the two water-transport models in two ways. (1) To compare the distributions of $\theta_{\mathrm{w}}$, we used the nonparametric MannWhitney $U$ test. A level of significance $p=0.05$ was chosen to decide whether the observed differences were statistically significant. The test was applied on the values obtained at noon for each day since melting at the snow surface occurred. (2) Measured $\theta_{\mathrm{w}}$ profiles were compared to model results of both simulations for all three sites. Again the nonparametric Mann-Whitney $U$ test was used to determine whether or not there was a difference between the distributions.

\section{RESULTS AND DISCUSSION}

\section{Wet-snow avalanche situation}

We briefly present the weather and avalanche situation of spring 2009. Figure 2 shows air temperature and snow depth at the Weissfluhjoch and Dorfberg test sites and the wetsnow avalanche activity index for the region around Davos during March and April 2009. Especially in the first 2 weeks of April 2009 and in mid-May, many wet-snow avalanches occurred. Most avalanches during the first cycle had start zones below 2200 ma.s.l., whereas the peak in mid-May included many avalanches with start zones reaching $3000 \mathrm{~m}$ a.s.l. Warm and sunny conditions led to increased meltwater production which triggered these two avalanche cycles. Most avalanches released due to a collapse of the basal layers caused by gradual weakening due to water infiltration. The snow/soil interface acted as a gliding bed (Mitterer and others, 2009). Observations in the Davos area showed that the arrival time of the water at the interface seemed to be crucial and varied depending on snow stratigraphy. A melt-freeze crust which had developed during a previous warm period in March and was subsequently covered by snowfalls in late March, acted as an impeding layer, but did not cause avalanches. Only later when water penetrated deeper into the snowpack did many slopes avalanche. Most wet-snow avalanches in the Davos area occurred around noon or in the early afternoon.

\section{Advance of wetting front and liquid water content}

The wetting front advance and thus the arrival of water at the bottom of the snowpack differed between the two watertransport models (Fig. 3). For both sites, Weissfluhjoch and Dorfberg, the water percolated more rapidly towards the bottom when using simulation mode II. Compared to continuous $\theta_{\mathrm{w}}$ measurements at $10 \mathrm{~cm}$ above ground (Fig. 3d) and outflow data recorded with the lysimeter (Fig. 3c), the mode II model estimated the arrival of the water at the bottom 6 days too early (19 April 2009) for Weissfluhjoch. Two peaks of high $\theta_{\mathrm{w}}$ observed at 25 and 27 April indicate that during this period water arrived at the bottom of the snowpack. The lysimeter data underline this assumption, with slightly more outflow during these days $\left(>5 \mathrm{~mm} \mathrm{~d}^{-1}\right)$. The records of outflow prior to this period seem to be very sporadic and may have been caused by laterally diverted water, since manual measurements of $\theta_{\mathrm{w}}$ did show dry-snow conditions near the bottom of the snowpack. 

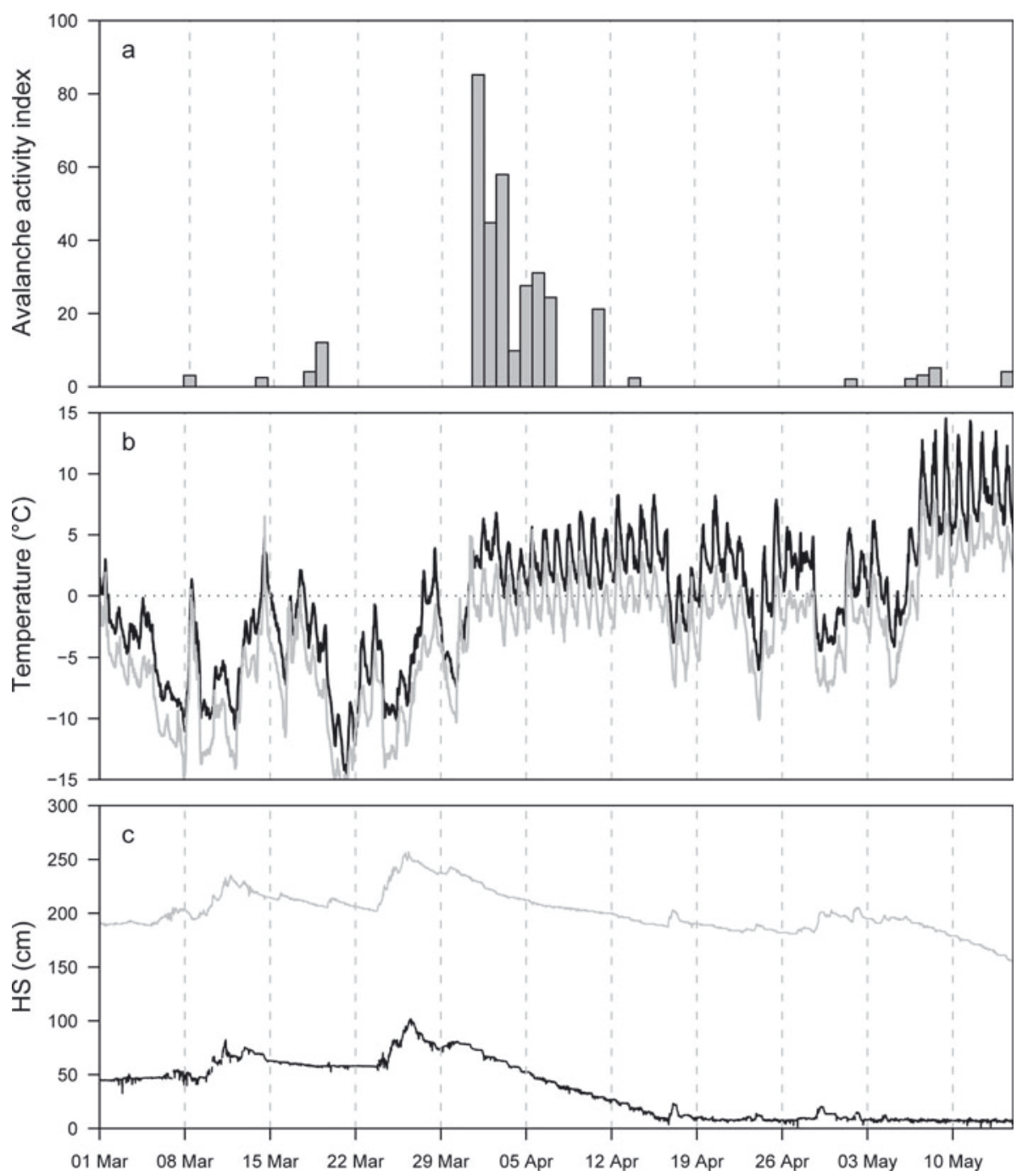

Fig. 2. (a) Avalanche activity index for wet-snow avalanches during March and April 2009 in the surroundings of Davos. (b) Air temperature for Weissfluhjoch (grey) and Dorfberg (black). (c) Snow depth for Weissfluhjoch (grey) and Dorfberg (black).

Using the mode I model, the water arrived at the bottom only by mid-May. Compared to the manual observations, this arrival time corresponded to the time when the total snowpack was already fully wet.

The results were similar for the Dorfberg site. While the arrival of the water using the model in mode II was in fair agreement with the onset of the highest avalanche activity (Fig. 2a) and observed values, the mode I model showed a delay of 9 days. In the case of the Dorfberg site, most slopes were almost without continuous snow cover or the snow depth was $<30 \mathrm{~cm}$ when the entire snowpack was modelled as wet with the water-transport model in mode I. The stepped advance of the wetting is not caused by possible ponding on melt-freeze crusts, but is rather due to the way water transport is implemented in SNOWPACK, suppressing the routing of water for $\theta_{\mathrm{r}}<0.08$ ( $8 \%$ by volume).

As only matrix flux behaviour is incorporated into the new water-transport model (mode II), the fair agreement between model and observation is remarkable. Snow is known to be a porous medium which favours the triggering of preferential flow patterns, so that models based on stable unsaturated flow are considered as not really suited to describe the water transport in snow (Waldner and others, 2004). For these two examples, however, the results are promising in regard to wetting-front advance and thus also for forecasting wet-snow avalanches that fail due to basal weakening.

The mode I water-transport model strongly underestimated the wetting-front advance. Only when the snowpack became considerably wet did the water drain to the bottom. This is probably because with ongoing melt and water transport the snowpack tends to become more homogeneous, i.e. snow stratigraphy will become more uniform than under dry-snow conditions. In this case, even simple wetting-front theory does a reasonably good job despite neglecting preferential flow effects (Davis and others, 2001). Since the first wetting and weakening at the surface (Trautman, 2008; Techel and Pielmeier 2009) and possibly ponding at the snow/soil interface seem to play an important role in the formation of wet-snow avalanches (Mitterer and others, 2009), the applicability of the default mode (mode I) for predicting wet-snow avalanches is questionable.

\section{Distribution of liquid water content and interaction with melt-freeze crusts}

Comparing the distribution of $\theta_{\mathrm{w}}$ over the entire snowpack, the difference between the two water-transport models tended to be larger for the Weissfluhjoch than for the Dorfberg site (Fig. 4). The difference was statistically significant over the entire observation period for Weissfluhjoch. 

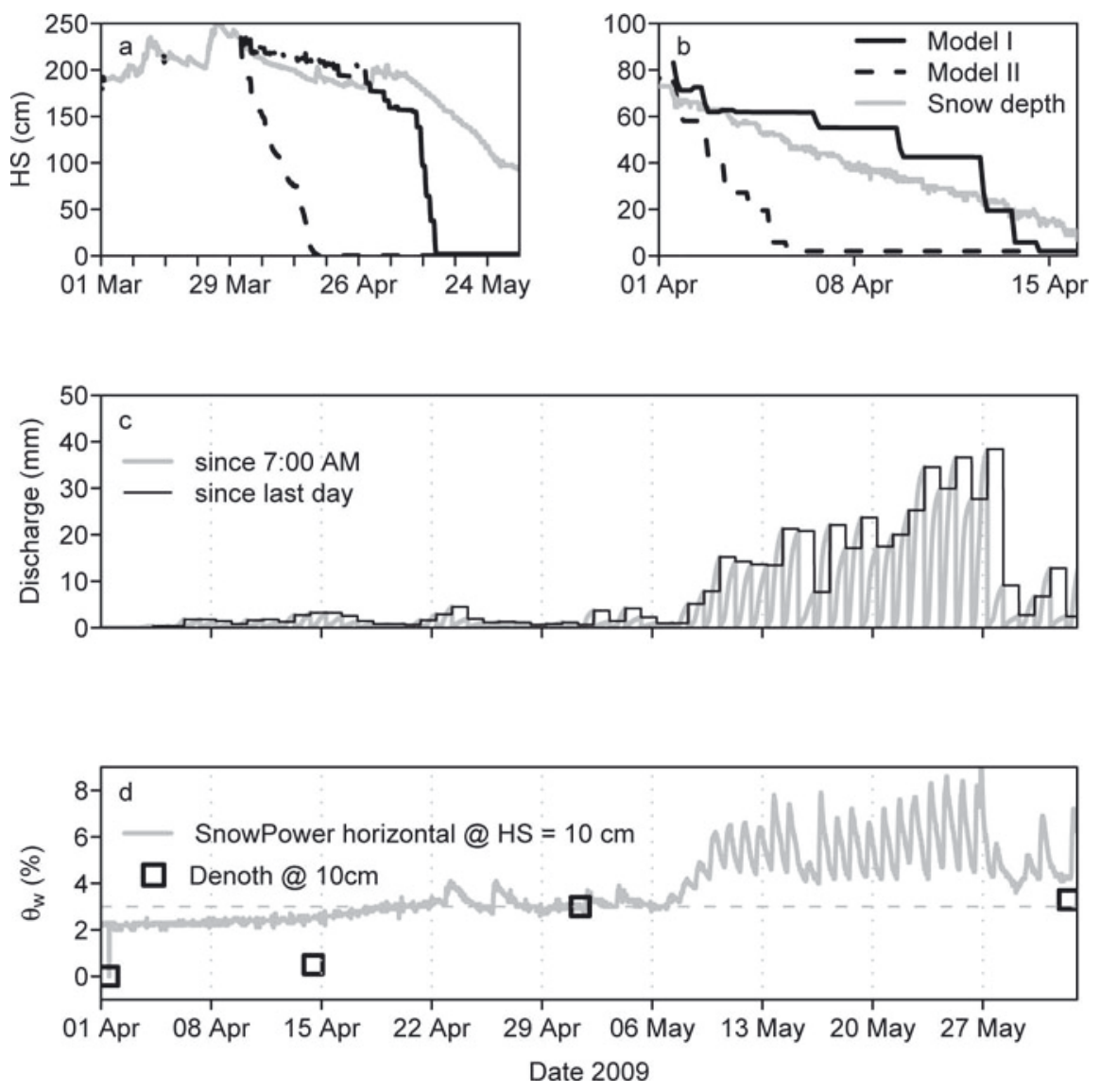

Fig. 3. Wetting-front advance calculated with water-transport modes I and II, and snow depth for (a) Weissfluhjoch and (b) Dorfberg. (c) Water discharge at Weissfluhjoch as recorded with a lysimeter. (d) Continuous measurements of $\theta_{\mathrm{w}}$ at Weissfluhjoch. Open squares indicate manual measurements.

This effect follows from the fact that the mode I model acts like a tipping bucket and large parts of the lower snowpack remained dry, whereas the mode II model already simulated liquid water. However, the discrepancy lasted until the end of the observation period when both models simulated wet conditions. With both models the $\theta_{\mathrm{w}}$ levelled off to a value of $3-4 \%$ by volume as soon as the entire snowpack was wet. This observation suggests that variations in grain-size difference that might cause different flow regimes were not large. Rather low variation in water content with frequently extremely low values characterized the mode II simulations (Fig. 4), whereas many extremely high values were typical for mode I. For the Dorfberg site the results were slightly different. With mode I there were more variations, whereas with mode II the $\theta_{\mathrm{w}}$ levelled off to a value of $\sim 3 \%$ by volume. On most days the liquid water distributions did not differ significantly ( $U$ test) between the two water-transport modes.

Figure 5 shows observed and modelled $\theta_{\mathrm{w}}$ profiles from the beginning of the wetting at the snow surface until the snowpack was completely wet at the Weissfluhjoch study site. The first wetting of the snow was well reproduced by SNOWPACK, suggesting that the energy exchange at the surface is well captured within the model (Fig. 5a). On the first observation day (1 April 2009), the penetration of a considerable amount of water modelled with mode I was in fair agreement with the observations. With mode II, penetration depth was overestimated and values of water content were too large. On the other three days, the model results did not agree well with the observations (Fig. 5b-d).
Ponding-detection results on hydraulic, less permeable layers such as melt-freeze crusts were ambivalent. The mode II model reproduced ponding on a crust (on 1 May 2009 at $175 \mathrm{~cm}$ ) or at the snow/soil interface (on 1 May 2009), but dominant crusts observed in manual profiles (at 150, 100 or $50 \mathrm{~cm}$; shaded area in Fig. 5) were not reproduced with either of the models. The main problem is that in both model runs, these crusts were not simulated, though SNOWPACK can simulate refreezing of backed-up water. A possible cause for missing a crust is that the energy for refreezing the water was not available, since the modelled snow temperature was too high (i.e. close to $0^{\circ} \mathrm{C}$ ). Another reason may be that, for example, the crust at $100 \mathrm{~cm}$ (Fig. 4c) originated from a capillary barrier caused by a layer of buried surface hoar. As SNOWPACK missed simulating the formation of the surface hoar layer, the mode II model, which in principle can reproduce capillary barriers (Hirashima and others, 2010), could also not capture this feature.

Furthermore, the model tended in both modes to transform melt-freeze crusts into melt forms too early. Manual observations have shown that melt-freeze crusts can last for several weeks despite wet conditions. The underestimation and/or lack of these hydraulic barriers is a great disadvantage, because potential failure layers cannot be detected. In addition, melt-freeze crusts are suggested to be important for triggering preferential flow paths (Jordan and others, 2008). It is essential to create a method that reproduces the build-up of internal ice lenses or melt-freeze crusts to be able to capture ponding and in a further step the possible 

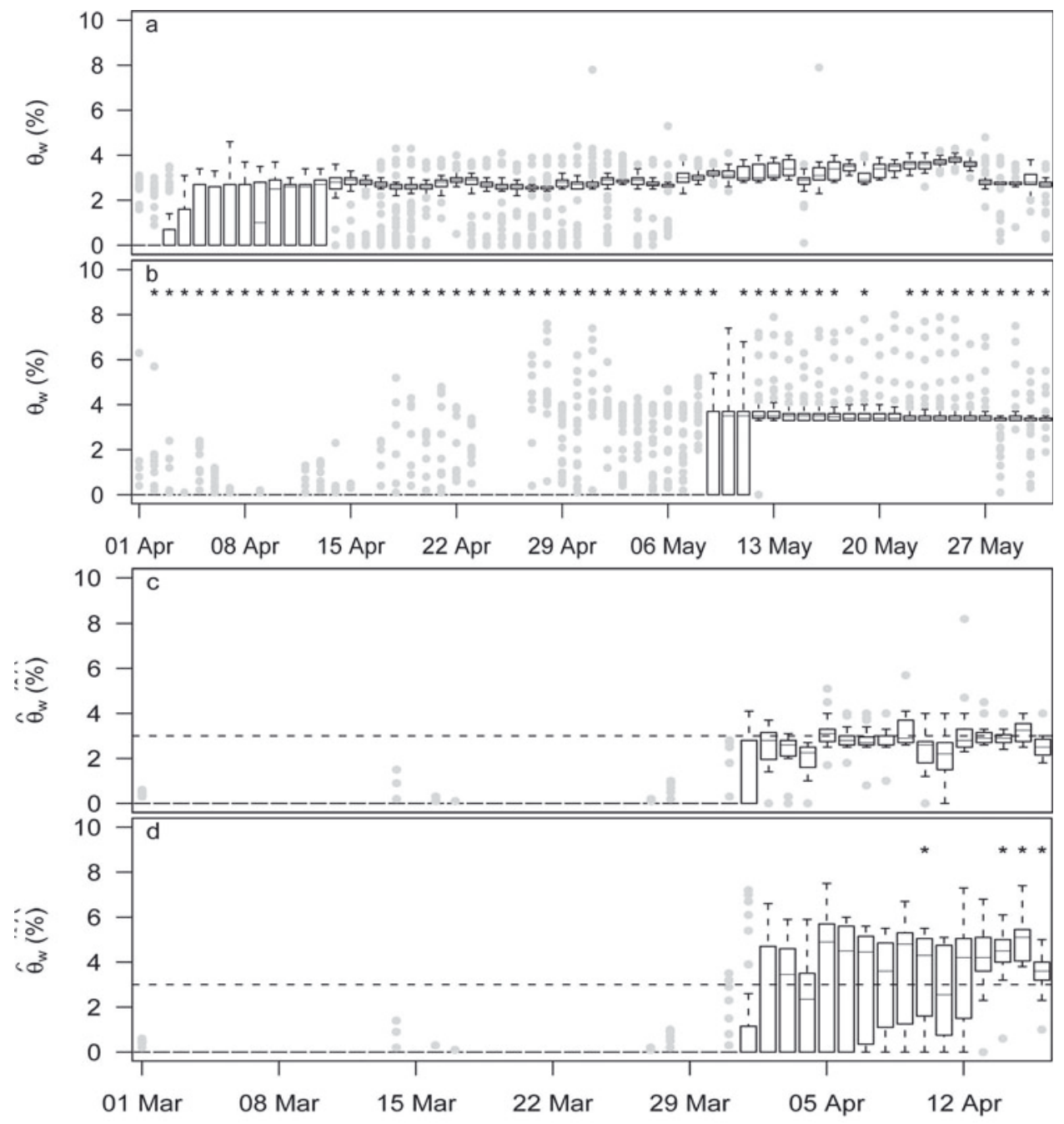

Date in 2009

Fig. 4. Box plots of $\theta_{\mathrm{w}}$ for the Weissfluhjoch site with (a) water-transport mode II and (b) mode l, and for the Dorfberg site with (c) water-transport mode II and (d) mode I. Boxes show interquartile range, whiskers extend to 1.5 times the interquartile range, and grey dots are outliers. Asterisks indicate those days when $\theta_{\mathrm{w}}$ distributions obtained with mode I and mode II model runs were significantly different ( $U$ test).

triggering of preferential flow. Preferential flow might be captured by introducing a parameterization based on a statistical approach.

\section{Grain size and detection of capillary barriers}

Only for the Flüela Hospiz site a capillary barrier was observed in the field and successfully modelled with SNOWPACK. Measurements were collected on 10 May 2009 at the crown of a wet-snow slab avalanche which had released spontaneously in the late afternoon of the previous day. A capillary barrier seemed to have acted as the failure layer. Figure 6 compares measured and modelled $\theta_{\mathrm{w}}$ and grain size. Using the mode II model, the effect of capillary impedance was reproduced very well. The mode I model did not capture this effect, as it is not implemented. The results show that it was possible to reproduce capillary barrier effects using the mode II model, which is encouraging and in agreement with observations made in the field (Fig. 5).

There are only a few cases (e.g. Fierz and Föhn, 1995) in which a capillary barrier could be detected as a failure layer. One reason might be that the currently available dielectric measurement devices are not designed for this purpose. The spatial sample resolution integrates over a volume too large to detect locally high amounts of liquid water which are expected above capillary barriers. Small ice lamellae which develop when water ponded on capillary barriers refreezes show that these wet layers tend to have a thickness of a few $\mathrm{mm}$. In addition, measurements are mostly destructive. Correct modelling might help to detect such mechanical features of wet snow.

\section{CONCLUSIONS}

We performed simulations of $\theta_{\mathrm{w}}$ using the 1-D numerical snow-cover model SNOWPACK. Within the numerical model we applied two different water-transport model schemes and compared the results with observed data. We focused on the arrival of liquid water at the bottom of the snowpack, and possible ponding at hydraulic or capillary barriers, since these factors should be directly related to wetsnow avalanche formation.

We used two different water-transport schemes implemented in SNOWPACK. There were significant differences between the two water-transport modes concerning the arrival time and the distribution of $\theta_{\mathrm{w}}$ in the snowpack (Figs 2 and 3), mainly due to the different approaches to 

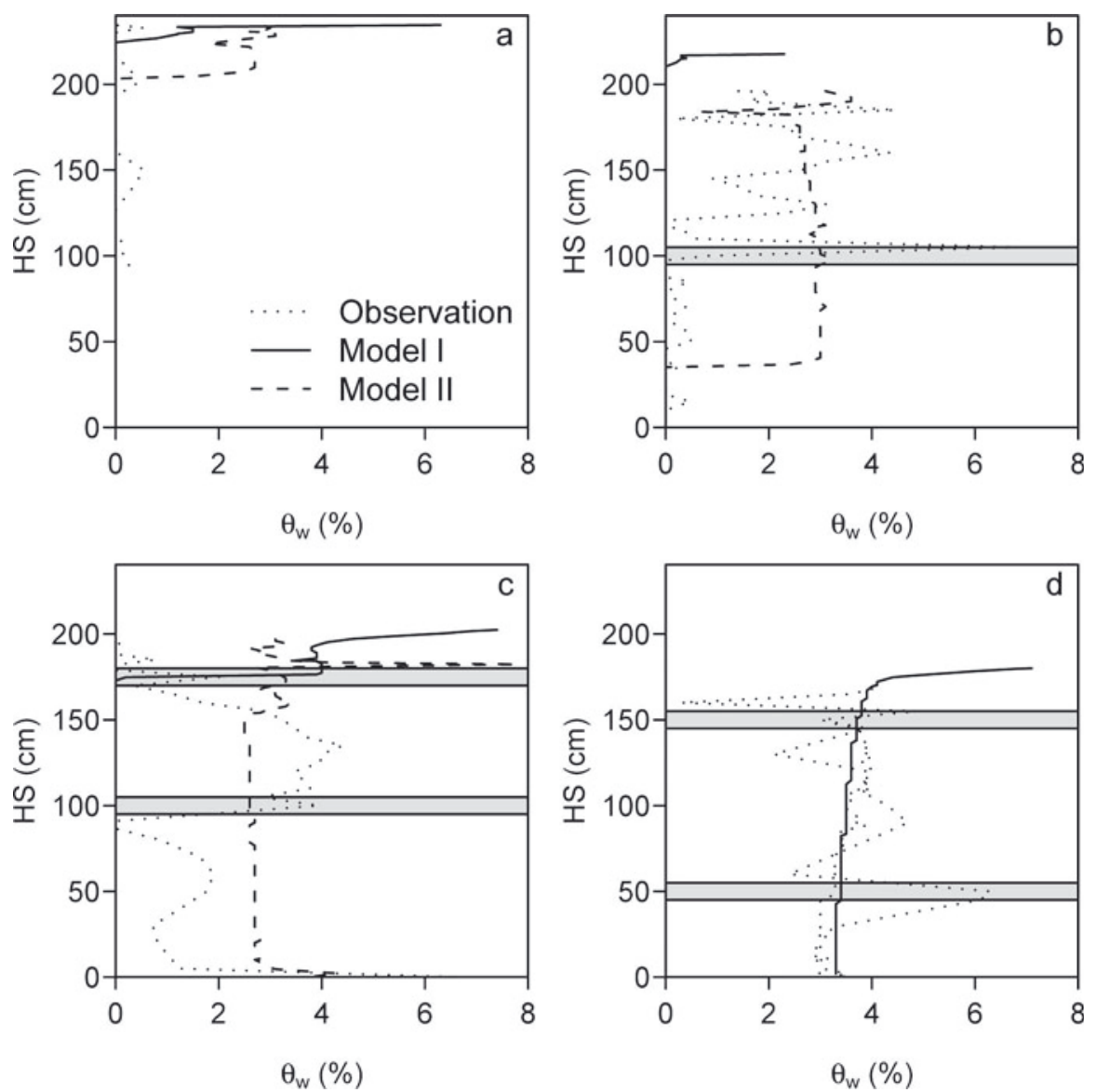

Fig. 5. Comparison of the two modelled $\theta_{\mathrm{w}}$ profiles with measured data for four days at the Weissfluhjoch test site: (a) 1 April 2009 ; (b) 14 April 2009; (c) 1 May 2009; and (d) 14 May 2009. Grey boxes represent manually observed melt-freeze crusts.

implementing the water transport. Compared to local avalanche activity at the Dorfberg site and measured data at the Weissfluhjoch site, the mode II transport model estimated the arrival of water at the bottom a little too early or at about the right time.

Modelled values of $\theta_{\mathrm{w}}$ were mostly in the range of the transition between the pendular and the funicular regime. Both models reproduced ponding on crusts either located at the snow surface or within the snowpack if they were previously formed at the surface and subsequently buried. As refreezing of percolating water is not captured well with either model, ponding on this type of crust could not be reproduced. We suggest improving this process, as it also has a major impact on the possible triggering of preferential flow. The mode II model proved to be able to reproduce the formation of capillary barriers.
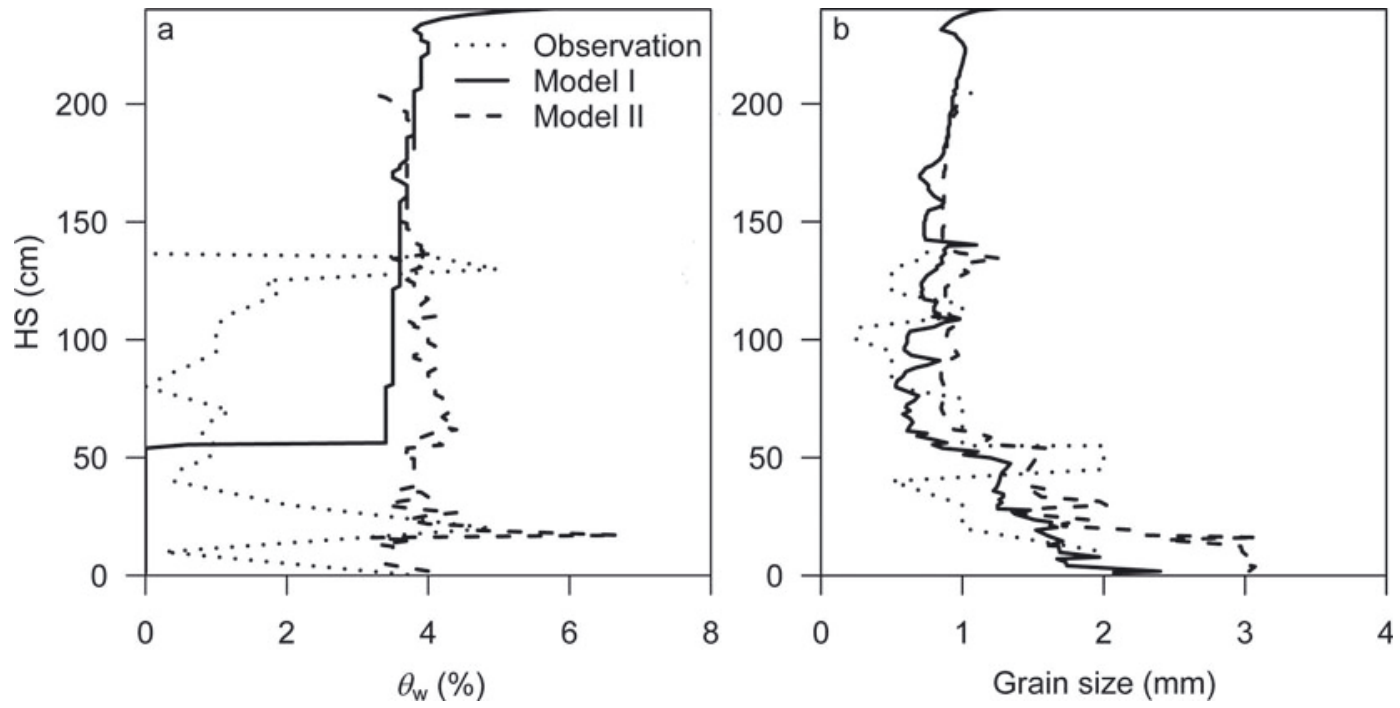

Fig. 6. (a) $\theta_{\mathrm{w}}$ and (b) grain size for the Flüela Hospiz station on 10 May 2009. Mode II represents results obtained with the new watertransport model; mode I represents the default mode. 
As our database is limited, some of our results might be influenced by the specific conditions we observed in the spring of 2009. However, many results such as the difference in arrival time between the two water-transport modes are probably generally valid. Nevertheless, more data for well-instrumented sites should be collected to corroborate our results. Further research must also be done concerning preferential flow patterns and the effect of $\theta_{\mathrm{w}}$ for wet-snow instability.

\section{ACKNOWLEDGEMENTS}

The study was funded by the Swiss National Science Foundation (grant 200021-126889) and the European Commission (FP7 STREP project HYDROSYS, grant 224416, DG INFSO). For stimulating discussions and help with the SNOWPACK model simulations we are grateful to C. Fierz.

\section{REFERENCES}

Baggi, S. and J. Schweizer. 2009. Characteristics of wet-snow avalanche activity: 20 years of observations from a high alpine valley (Dischma, Switzerland). Natur. Hazards, 50(1), 97-108.

Bartelt, P. and M. Lehning. 2002. A physical SNOWPACK model for the Swiss avalanche warning. Part I: numerical model. Cold Reg. Sci. Technol., 35(3), 123-145.

Bhutiyani, M.R. 1994. Field investigations on meltwater percolation and its effect on shear strength of wet snow. In Agrawal, K.C., ed. Proceedings of the International Symposium on Snow. Manali, Snow and Avalanche Study Establishment, 200-206.

Brun, E. and L. Rey. 1987. Field study on snow mechanical properties with special regard to liquid water content. IAHS Publ. 162 (Symposium at Davos 1986 - Avalanche Formation, Movement and Effects), 183-192.

Davis, R., R. Jordan, S. Daly and G. Koenig. 2001. Validation of snow models. In Anderson, M.G. and P.D. Bates, eds. Model validation: perspectives in hydrological sciences. Chichester, John Wiley and Sons, 261-292.

Denoth, A. 1980. The pendular-funicular liquid transition in snow. J. Glaciol., 25(91), 93-97.

Denoth, A. and 6 others. 1984. A comparative study of instruments for measuring the liquid water content of snow. J. Appl. Phys., 56(7), 2154-2160.

Fierz, C. and P.M.B. Föhn. 1995. Long-term observation of the water content of an alpine snowpack. In Proceedings of the International Snow Science Workshop, 30 October-3 November 1994, Snowbird, Utah, U.S.A. Snowbird, UT, ISSW '94 Committee, 117-131.

Hillel, D. 2004. Introduction to environmental soil physics. Burlington, MA, etc., Elsevier Academic Press.

Hirashima, H., S. Yamaguchi, A. Sato and M. Lehning. 2010. Numerical modelling of liquid water movement through layered snow based on new measurements of the water retention curve. Cold Reg. Sci. Technol., 64(2), 94-103.

Jordan, R. 1991. A one-dimensional temperature model for a snow cover: technical documentation for SNTHERM.89. CRREL Spec. Rep. 91-16.

Jordan, R.E., M.R. Albert and E. Brun. 2008. Physical processes within the snow cover and their parameterization. In Armstrong, R.L. and E. Brun, eds. Snow and climate: physical processes, surface energy exchange and modeling. Cambridge, Cambridge University Press, 12-69.

Kattelmann, R. 1985. Wet slab instability. In Proceedings of the International Snow Science Workshop, 24-27 October 1984, Aspen, Colorado, U.S.A. Aspen, CO, ISSW '84 Committee, 102-108.
Kattelmann, R.C. 1986. Measurements of snow layer water retention. In Kane, D.L., ed. Symposium: Cold Regions Hydrology, 22-25 July 1986, Fairbanks, Alaska. Proceedings. Bethesda, MD, American Water Resources Association, 377-386. (AWRA Technical Publication Series TPS-86-1.)

Lehning, M., P. Bartelt, B. Brown, C. Fierz and P. Satyawali. 2002a. A physical SNOWPACK model for the Swiss avalanche warning. Part II: snow microstructure. Cold Reg. Sci. Technol., 35(3), 147-167.

Lehning, M., P. Bartelt, B. Brown and C. Fierz. 2002b. A physical SNOWPACK model for the Swiss avalanche warning. Part III: meteorological forcing, thin layer formation and evaluation. Cold Reg. Sci. Technol., 35(3), 169-184.

McClung, D. and P. Schaerer. 2006. The avalanche handbook. Third edition. Seattle, WA, The Mountaineers.

Mitterer, C., R. Mott and J. Schweizer. 2009. Observations and analysis of two wet-snow avalanche cycles. In Schweizer, J. and A. van Herwijnen, eds. Proceedings of the International Snow Science Workshop, 27 September-2 October 2009, Davos, Switzerland. Davos, WSL Institute for Snow and Avalanche Research SLF, 262-266.

Mualem, Y. 1976. A new model for predicting the hydraulic conductivity of unsaturated porous media. Water Resour. Res., 12(3), 513-522.

Peitzsch, E., K.W. Birkeland and K. Hansen. 2008. Water movement and capillary barriers in a stratified and inclined snowpack. In Campbell, C., S. Conger and P. Haegeli, eds. Proceedings of the International Snow Science Workshop, 21-27 September 2008, Whistler, British Columbia, Canada. International Snow Science Workshop, 179-187.

Romig, J.M., S.G. Custer, K.W. Birkeland and W.W. Locke. 2005. March wet avalanche prediction at Bridger Bowl Ski Area, Montana. In Elder, K., ed. Proceedings of the International Snow Science Workshop, 19-24 September 2004, Jackson Hole, WY, U.S.A. International Snow Science Workshop, 598-607.

Schneebeli, M. 2004. Mechanisms in wet snow avalanche release. In Proceedings of the International Symposium on Snow Monitoring and Avalanches. Manali, Snow and Avalanche Study Establishment, 75-77.

Schweizer, J., J.B. Jamieson and M. Schneebeli. 2003a. Snow avalanche formation. Rev. Geophys., 41(4), 1016. (10.1029/ 2002RG000123.)

Schweizer, J., K. Kronholm and T. Wiesinger. 2003b. Verification of regional snowpack stability and avalanche danger. Cold Reg. Sci. Technol., 37(3), 277-288.

Stähli, M., M. Stacheder, D. Gustafsson, M. Schlaeger, M. Schneebeli and A. Brandelik. 2004. A new in situ sensor for large-scale snow-cover monitoring. Ann. Glaciol., 38, 273-278.

Techel, F. and C. Pielmeier. 2009. Wet snow diurnal evolution and stability assessment. In Schweizer, J. and A. van Herwijnen, eds. Proceedings of the International Snow Science Workshop, 27 September-2 October 2009, Davos, Switzerland. Birmensdorf, Swiss Federal Institute for Forest, Snow and Landscape Research, 256-261.

Trautman, S. 2008. Investigations into wet snow. Avalanche Rev., 26(4), 16-17.

Van Genuchten, M.T. 1980. A closed-form equation for predicting the hydraulic conductivity of unsaturated soils. Soil Sci. Soc. Am., J., 44(5), 892-898.

Waldner, P., M. Schneebeli, U. Schultze-Zimmermann and H. Flühler. 2004. Effect of snow structure on water flow and solute transport. Hydrol. Process., 18(7), 1271-1290.

Wankiewicz, A. 1979. A review of water movement in snow. In Colbeck, S.C. and M. Ray, eds. Modeling of Snow Cover Runoff, 26-28 September 1978, Hanover, New Hampshire. Proceedings. Hanover, NH, U.S. Army Corps of Engineers. Cold Regions Research and Engineering Laboratory, 222-252.

Yamaguchi, S., T. Katsushima, A. Sato and T. Kumakura. 2010. Water retention curve of snow with different grain sizes. Cold Reg. Sci. Technol., 64(2), 87-93. 